\title{
An Employee Influenza Immunization Initiative in a Large University Managed Care Setting
}

OBJ ECTIVE: To implement an employee influenza-immunization initiative, assess employee population characteristics, and estimate the cost savings to the university and its managed health care system.

DESIGN: An interdisciplinary team of health care providers vaccinated employees at mobile sites. A survey was distributed to assess population factors and flu-vaccine status of employees. A literature-based economic analysis was conducted to estimate savings.

SETTING: Large university campus with a major medical center.

MAIN OUTCOME MEASURES: Total number of employees vaccinated compared to prior years, employee population characteristics, and estimated cost savings (direct and indirect costs).

RESULTS: The immunization effort reach-ed 5,730 employees on the main campus, an increase of more than 2,000 employees from the previous year. of employees completing an on-site survey, nearly $30 \%$ were first-time influenza vaccine recipients and $85.5 \%$ were enrolled in one of the university health plans. The direct cost for the initiative was approximately $\$ 25,000$ while the estimated cost savings approached $\$ 400,000$.

CONCLUSION: The focused influenza immunization initiative increased numbers of employees vaccinated on campus. Survey results provided a description of the employees vaccinated. The employer-driven program was predicted to provide cost savings.

KEYWORDS: Influenza, vaccination, immunization, managed care, pharmacist, interdisciplinary

J Managed Care Pharm 2001: 219-23 by Jeri J. Sias, Stephanie Cook, Thomas W olfe, Gavin Baumgardner, and Pam Salsberry

I

nfluenza and pneumonia, combined, represent the sixth leading cause of death in the United States. Hospitalizations attributable to influenza and pneumonia number over 100,000 each year. Additionally, influenza accounts for an average of 20,000 deaths annually. ${ }^{1,2}$ Influenza can cause significant morbidity and mortality in elderly patients and in persons of any age with chronic medical conditions. In addition to the impact of influenza in these high-risk groups, the average healthy working adult is also adversely affected socially and economically. Influenza outbreaks have far-reaching consequences. Communities as a whole can benefit from innovative approaches to decrease the prevalence of future outbreaks.

The National Vaccine Advisory Committee, recognizing the need for improved rates of adult vaccination, has evaluated nontraditional settings for adult immunization, including the workplace and pharmacies. ${ }^{3}$ W hile current influenza vaccination recommendations target specific age and high-risk groups, the need and benefit for vaccination in healthy working adults remains less clear. According to Nichol et al., influenza vaccination of healthy, working adults had positive health-related and economic outcomes. ${ }^{4}$ In their evaluation, the estimated sick leave per year attributable to upper respiratory illness was approximately 1.22 days for nonvaccinated, healthy, working adults, compared with 0.7 days for vaccinated adults $(0.52$ sick days saved per employee per year). Additionally, their study focused on the potential economic benefits to employers by evaluating direct and indirect costs of vaccinating employees.

\section{Objective}

This descriptive report outlines a worksite influenza-vaccination initiative delivered by an interdisciplinary team. The major emphasis of this initiative was to increase influenza-vaccination rates among university employees by providing convenient and accessible services. Characteristics and influenza-immunization history of the vaccinated population were assessed. Potential cost savings to the university and its managed health care system were evaluated by applying a literature-based model. ${ }^{4}$

\section{- Practice Description/Setting}

The Ohio State University (OSU) has approximately 24,500 employees. The OSU Managed Health Care System, Inc. (MHCS), the principal health care provider to employees in the 
university, has a history of working to improve access to wellness care through mobile sites. Health-risk assessments by an interdisciplinary team of nurses, pharmacists, and health educators are provided to all employees as a university benefit. Additionally, the university's managed health plans have contracted with the outpatient pharmacy to provide cholesterolmanagement and smoking-cessation services.

Traditional sites for influenza vaccinations have included the employee health center, mobile campus sites, and physicians' offices. For the 1997-98 and 1998-99 influenza seasons, the estimated number of influenza vaccinations provided in these sites on the main campus was 2,070 and 3,230, respectively (see Figure 1, below). Based on the number of past influenza vaccines on campus, the history of interdisciplinary care in mobile sites, and a literature-based assessment of influenzavaccination benefits among working adults, OSU MHCS, Inc., recognized the need to improve influenza-vaccination rates. The health plan made a commitment to provide accessible influenza-immunization services to campus employees. An interdisciplinary team of health care providers was used to create additional sites around campus.

\section{- Practice Innovation}

The university managed health care system partnered with the employee health center, the faculty and staff wellness program, the college of pharmacy, and the office of human resources to provide an influenza-immunization initiative. Between October and December of 1999, influenza immunizations were provided at no cost to employees at 25 sites around campus. Mobile sites were interspersed throughout the campus to be accessible to most of the university employee population. At most sites, immunizations were given over a four-hour period of time. The interdisciplinary team included pharmacists, nurses, a nurse practitioner, a physician, and a health educator. Physicians' offices also continued to offer influenza-vaccination services.

To encourage employee participation, the program was marketed through campus-newspaper advertisements, individual e mail messages, and an Internet sign-up/appointment model. Individuals were recruited from departments throughout campus to reserve rooms for vaccination and communicate with departments in or near their mobile site. E-mail messages offering Internet scheduling were sent to employees to encourage their participation. The secured Internet site was developed to facilitate employee sign-up and to help anticipate the number of vaccinations that would be provided on each day. After scheduling by Internet, employees received an e-mail reminder of the date and location for vaccination. Maps highlighting building sites for the immunization initiative were distributed in the campus newspaper.

Educational materials on the influenza vaccine and other adult immunizations were made available to employees while they waited for vaccination. Employees were asked immuniza- tion-screening questions at registration sites by each provider. While vaccines were prepared, patients completed consent forms. Adult-immunization record cards and a survey tool to assess patient characteristics and vaccination history were also distributed to employees.

\section{main Outcome Measures}

To assess the effectiveness and population characteristics of the influenza immunization initiative, data were collected and evaluated on employees vaccinated and surveyed. The total number of university employees who were vaccinated was tabulated based on sign-in records at each site and through physician office International Classification of Disease, 9th edition (ICD-9) codes. After the initiative was completed in December 1999, vaccine recipients were matched to university employment records to obtain demographic information and employment data.

The survey was distributed only at main campus mobile sites and the employee health center. It assessed the employee's health plan enrollment and influenza-vaccination history, and asked their opinion of the convenience of the vaccination program. Survey results in the employee health center and at mobile sites were compared using a chi-square test (SAS).

Using the employment data, the average salary, including benefits, was calculated. To determine the potential reduction in the number of sick days and the potential cost savings to the university and the managed health care system, the direct and indirect costs were estimated according to the Nichol model. ${ }^{4}$ In this model, medical care costs were estimated based on the mean fee in 1994 for a physician's office visit for an established patient. They estimated half of employees experiencing side

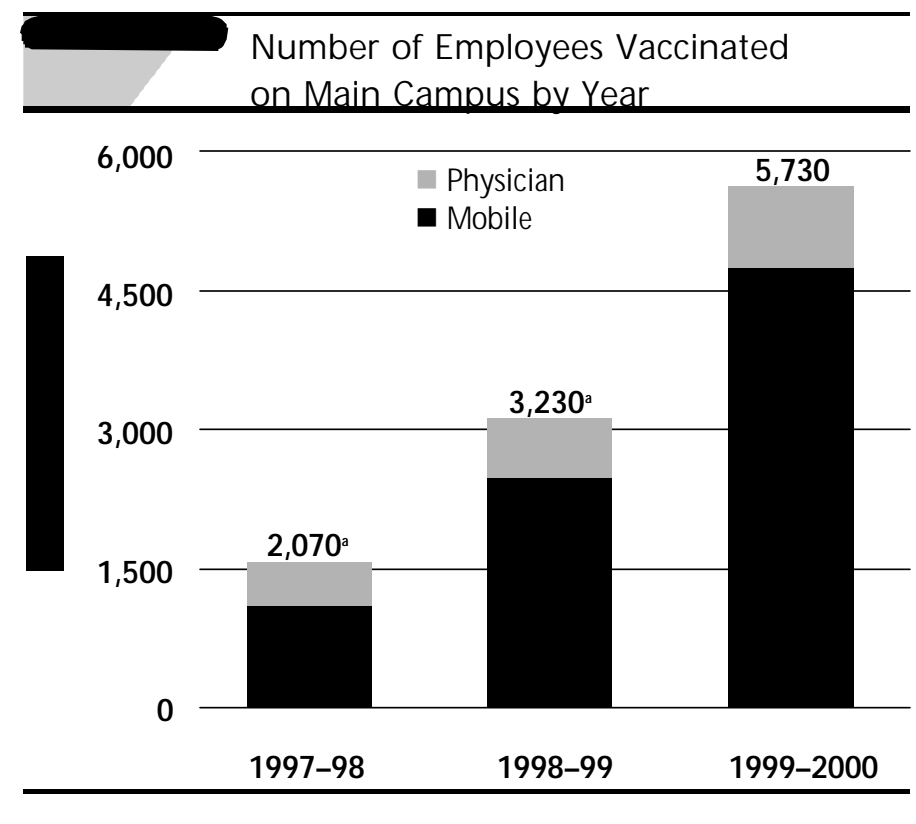


An Employee Influenza Immunization Initiative in a Large University Managed Care Setting

\begin{tabular}{l|c|c}
\hline \multicolumn{3}{|c}{ Employee Demographics } \\
\hline Characteristics & $\begin{array}{c}\text { Vaccinated } \\
\text { Population } \\
\mathbf{n = 4 , 3 5 8}\end{array}$ & $\begin{array}{c}\text { Total University } \\
\text { Employees } \\
\mathbf{n = 2 4 , 5 5 4}\end{array}$ \\
\hline Mean Age & 44.8 & 44 \\
\hline Female (\%) & 58.4 & 49.5 \\
\hline Job Classification & $2,055(47.2)$ & $12,601(51.3)$ \\
\hline $\begin{array}{l}\text { Administrative/ } \\
\text { professional (\%) }\end{array}$ & $1,263(29.0)$ & $5,278(21.5)$ \\
\hline $\begin{array}{l}\text { Classified civil } \\
\text { service (\%) }\end{array}$ & $1,040(23.9)$ & $6,675(27.2)$ \\
\hline Faculty (\%)
\end{tabular}

${ }^{a}$ Represents the number of patients who have demographic information available through employment records.

Survey Results $(n=3,045)$

\begin{tabular}{l|c|r|r}
\hline Survey Question & Response & Number $^{\mathbf{a}}$ & Percent $^{\mathbf{a}}$ \\
\hline Do you have health & Yes & 2,993 & 98.3 \\
insurance? & No & 44 & 1.4 \\
\hline Do you have university & Yes & 2,604 & 85.5 \\
health insurance? & No & 435 & 14.3 \\
\hline Is this your first time & Yes & 895 & 29.4 \\
receiving a flu vaccine? & No & 2,148 & 70.5 \\
\hline Did you get a flu vaccine & Yes & 1,634 & 53.7 \\
last year? & No & 1,403 & 46.1 \\
\hline Did convenience influence & Yes & 2,838 & 93.2 \\
you to get your flu shot at & No & 177 & 5.8 \\
this site? & & & \\
\hline
\end{tabular}

${ }^{a} \mathrm{~N}$ umbers may not total 3,045 (100\%) because of lack of response on some surveys.

effects would see a physician and that an estimated two days of work were lost per 100 vaccines due to side effects. The numbers of sick days ( 52 days/100 subjects) and physician office visits (24 visits/100 subjects) avoided due to upper respiratory illness were calculated as a difference in the rates between placebo and vaccine group.

The direct costs for this university initiative included program costs (advertisement, Internet start-up costs, providers, and vaccine/supplies) and estimated direct costs (medical care for side effects and medical care avoided). Indirect costs included the salary loss of one hour away from work for vaccination in addition to estimates of work loss due to side effects and work loss avoided as compared to nonvaccinated employees.

\section{Results}

In the 1999-2000 influenza season, a total of 6,624 employees were documented as being vaccinated by university providers (employee health, mobile units, and physician offices) at the main campus and regional campus sites. Of those employees, 5,730 were vaccinated on the main campus of the university (mobile sites/employee health: 5,081; physician offices: 649 ). This initiative increased vaccinations on the main campus by more than 2,000 and 3,000 vaccines compared to the two prior vaccine seasons (see Figure 1, page 220).

Only the employees vaccinated in employee health $(n=1,167)$ or at a mobile site $(n=3,914)$ on the main campus were analyzed (total $n=5,081$ ). Nearly $86 \%(4,358 / 5,081)$ of vaccinated employees were matched to human-resource files and had available demographic data (see Table 1, left). While there were 24,554 employees during the initiative, 17,837 were considered both benefits-eligible and worked on the main campus. Of these benefits-eligible main campus employees, $24.4 \%$ $(4,358 / 17,837)$ were vaccinated.

The total survey response rate was $60 \%(3,045 / 5,081)$. Ninety-eight percent of respondents reported having health insurance, with $85.5 \%$ indicating enrollment in one of the four university health plans. Employees who reported that this was their first influenza vaccination totaled $29.4 \%$. Forty-six percent of the surveyed employees reported that they did not get a flu shot last year. Convenience was cited as influential in receiving their vaccine in $93.2 \%$ of employees (see Table 2, left).

Survey return rates varied in the employee health center (22\%: 257/1,167) compared with mobile sites $(71.2 \%$ : $2,788 / 3,914)$. First-time vaccine recipients seemed to be more likely to use a mobile unit than the employee health center (mobile: $30.1 \%$, employee health: $21.8 \%, p=0.005$ ). These results suggest that the convenience offered by mobile sites enhanced immunization rates (mobile: 94.5\%, employee health: $90.6 \%, p=0.011$ ) (see Table 3, page 222).

An economic analysis was conducted using the model described by Nichol et al. ${ }^{4}$ The direct cost for the immunization initiative was $\$ 24,700$. The average hourly wage plus benefits for participants was $\$ 25.61$. When applying the Nichol model to the vaccinated population ( $n=5,081), 2,242$ sick days were projected to be saved for the year. ${ }^{4}$ The estimated total costsavings of vaccinating employees was $\$ 393,371$ (see Table 4, page 222). This amount suggests savings of $\$ 90.26$ ( $\$ 393,371 /$ $4,358)$ per employee vaccinated.

\section{- Discussion}

The findings from this project demonstrate benefits of a targeted worksite vaccination program. A total of 5,730 patients were vaccinated during the 1999-2000 season on the main campus, reflecting an increase in immunizations over the two previous 
An Employee Influenza Immunization Initiative in a Large University Managed Care Setting

seasons. At the time of analysis, 4,358 of the 5,081 participants in the mobile sites could be verified in the employer records. These matched records were later used to evaluate population demographics and to calculate potential cost-savings for the employer.

The surveys $(3,045)$ provided additional background information about the vaccinated employees that could not be obtained from employee or medical records alone. Almost half $(46 \%)$ of employees completing a survey did not receive a vaccination in the previous year, and $85.5 \%$ were enrolled in one of the university health plans. Results demonstrated that nearly $30 \%$ were first-time influenza vaccine recipients. Convenient access via mobile sites appeared to positively affect immunization rates.

The discrepancy observed in survey response rate between employee health $(21.9 \%)$ and the mobile sites $(71.2 \%)$ may be attributed to inconsistencies in survey distribution. The demographics and survey answers in employee health compared with mobile sites do suggest some differences and trends. It appears that more first-time flu vaccine recipients received their inoculations at mobile sites than in employee health centers. Employees receiving vaccines at mobile campus units reported convenience as a factor slightly more often than those who visited employee health centers.

The Ohio State University is self-insured (i.e., funds its own health plan). With $85.5 \%$ of surveyed participants enrolled in one of the university health plans, OSU MHCS, Inc., and the university, as an employer, both benefit from high participation in the initiative. To determine potential cost savings, a literature-based analysis by Nichol et al. was utilized. ${ }^{4}$ In this randomized, double-blind, placebo-controlled trial of influenza vaccination in 849 healthy, working adults in the MinneapolisSt. Paul region, an economic model of direct and indirect costs was developed.

In applying this model to this university's findings, a direct cost savings of $\$ 58,545$ and an indirect cost savings of $\$ 334,826$ were projected. The cost for medical care office visits in the Nichol study was adjusted to the 1999 Consumer Price Index. ${ }^{5}$ To determine potential work lost, the average university employee salary including benefits was used. In this setting, a more conservative time ( 1 hour instead of 30 minutes) was used to determine time away from work.

The Nichol study population $(n=424)$ compares to this university's vaccinated population $(4,358)$ in the following ways: Average age in the university population was 44.8 years in contrast to 39.2 years in the Nichol study. The proportion of female recipients was comparable between the university $(58.4 \%)$ and the Nichol study $(60.2 \%)$. Thirty percent of the university employees completing surveys reported first-time influenza vaccination compared with $74 \%$ in the Nichol study. We used the Nichol economic analysis as a guide for the potential benefits in the university setting.

\begin{tabular}{|c|c|c|c|}
\hline \multicolumn{4}{|c|}{$\begin{array}{l}\text { Comparison of Survey Responses of } \\
\text { Patients Receiving Flu Vaccine }\end{array}$} \\
\hline Variable & $\begin{array}{l}\text { Employee } \\
\text { Health }\end{array}$ & $\begin{array}{l}\text { Mobile } \\
\text { Unit }\end{array}$ & $p$ value \\
\hline Female (\%) & $\begin{array}{c}151(63.4) \\
n=238\end{array}$ & $\begin{array}{c}1,486(58.0) \\
n=2,546\end{array}$ & 0.1 \\
\hline $\begin{array}{l}\text { First-time influenza } \\
\text { vaccination }(\%)\end{array}$ & $\begin{array}{c}56(21.8) \\
n=257\end{array}$ & $\begin{array}{l}839(30.1) \\
n=2,786\end{array}$ & 0.005 \\
\hline $\begin{array}{l}\text { Convenience was a } \\
\text { factor in getting flu } \\
\text { vaccination (\%) }\end{array}$ & $\begin{array}{c}230(90.6) \\
n=254\end{array}$ & $\begin{array}{c}2,608(94.5) \\
n=2,761\end{array}$ & 0.011 \\
\hline
\end{tabular}

Note: Total Employee H ealth responses ( $n=257)$, Total M obile U nit Responses $(n=2,788)$

\begin{tabular}{|c|c|}
\hline \multicolumn{2}{|l|}{ Economic Analysis } \\
\hline Variable & $\begin{array}{c}\text { Cost } \\
\text { (Savings) } \\
n=4,358\end{array}$ \\
\hline \multicolumn{2}{|l|}{ Direct costs } \\
\hline Vaccination program costs ${ }^{\mathrm{a}}$ & $\$ 24,700$ \\
\hline $\begin{array}{l}\text { Medical care for side effects (1 office } \\
\text { visit per } 100 \text { subjects) })^{b}\end{array}$ & $\$ 3,619$ \\
\hline $\begin{array}{l}\text { Medical care avoided ( } 24 \text { office visits } \\
\text { for upper respiratory illness per } 100 \\
\text { subjects) }\end{array}$ & $(\$ 86,864)$ \\
\hline Total direct costs & $(\$ 58,545)$ \\
\hline \multicolumn{2}{|l|}{ Indirect costs } \\
\hline $\begin{array}{l}\text { Work time lost for vaccination } \\
\text { (1 hour per vaccination })^{c}\end{array}$ & $\$ 111,608$ \\
\hline $\begin{array}{l}\text { Work loss due to side effects ( } 2 \text { days } \\
\text { per } 100 \text { subjects) }\end{array}$ & $\$ 17,857$ \\
\hline $\begin{array}{l}\text { Work loss avoided ( } 52 \text { days for upper } \\
\text { respiratory illness per } 100 \text { subjects) }\end{array}$ & $(\$ 464,291)$ \\
\hline Total indirect costs & $(\$ 334,826)$ \\
\hline Net costs & $(\$ 393,371)$ \\
\hline \multicolumn{2}{|c|}{$\begin{array}{l}\text { aIncluded costs for advertisement, personnel, vaccine/supplies, and Internet } \\
\text { start-up. } \\
{ }^{b} \text { Cost for physician visit derived from Nichol et al. }{ }^{4}(\$ 69.51) \text { and adjusted } \\
\text { for inflation ( } \$ 83.05 / v i s i t){ }^{5} \\
{ }^{5} \text { Cost of work loss was determined by averaging the salaries (hourly wage } \\
+ \text { benefits) based on job classification benefits ( } \$ 25.61 / \text { hour, } \$ 204.88 / \text { eight } \\
\text { hour day). }\end{array}$} \\
\hline
\end{tabular}


We believe that all of the estimated values reflect conservative numbers and the potential savings are possibly greater than those reported. Further analysis of vaccinated employees in high-risk categories (e.g., persons with diabetes or asthma) compared with a control group should also be conducted.

\section{Conclusion}

This interdisciplinary initiative was successful in increasing influenza immunizations during the 1999-2000 influenza season. Approximately one-third of employees indicated that they had never before received a flu vaccine, and more than $90 \%$ cited convenience as influential in receiving a vaccine. It is possible that access and convenience to vaccine services increased vaccination rates.

Based on the literature, the potential cost savings to the university and managed health care systems was nearly $\$ 400,000$, or approximately $\$ 90$ per employee. In addition, the university com- munity was estimated to save more than 2,000 sick days. These interdisciplinary immunization efforts could prove to be viable partnerships in other settings as well. Such partnerships could benefit employees, employers, and the health care system, leading to decreased sick days and increased cost savings to the community.

\section{References}

1. Prevention and control of influenza: recommendations of the advisory committee on immunization practices (ACIP). MMWR 1999; 48: 1-28.

2. Notice to readers: Update recommendations from the Advisory Committee on Immunization Practices in response to delays in supply of influenza vaccine for the 2000-01 Season. MMWR 2000; 49(39): 888-92.

3. Adult immunization programs in nontraditional settings: quality standards and guidance for program evaluation. MMWR 2000; 49(RR-1): 1-13.

4. Nichol KL et al. The effectiveness of vaccination against influenza in healthy, working adults. N Eng J Med 1995; 333: 889-93.

5. Bureau of Labor Statistics. Consumer Price Index-All Urban Consumers (Current Series). U.S. Medical Care. Base Period: 1982-84: 100. Series ID: 